\title{
ОСОБЕННОСТИ ГОСУДАРСТВЕННОЙ ПОДДЕРЖКИ СОЦИАЛЬНО ОРИЕНТИРОВАННЫХ НЕКОММЕРЧЕСКИХ ОРГАНИЗАЦИЙ
}

\section{FEATURES OF STATE SUPPORT \\ OF SOCIALLY ORIENTED NON-PROFIT ORGANIZATIONS}

\section{E. Bagirova \\ M. Lazareva}

Summary. In this paper, the characteristics of socially oriented nonprofit organizations are considered, and the main measures of state support for socially oriented non-profit organizations are presented. The main state programs supporting the activities of socially oriented non-profit organizations are identified.

Keywords: state support, socially oriented non-profit organizations, state regulation, resource center for socially oriented non-profit organizations.
Некоммерческий сектор является важнейшим в решение различных социальных проблем и в становлении культурного общества России. Центральным звеном в данном секторе является социально ориентированные некоммерческие организации.

В последнее время произошел поворот государства в сторону «третьего сектора» экономики. Некоммерческие организации (НКО) уже являются партнерами государственных органов власти в оказании гражданам социальных услуг [3, с. 87]. Но все же вклад НКО в российский ВВП до сих пор очень мал всего около 1\%, а занято в «третьем секторе» лишь 1,1\% экономически активного населения страны.

Государственное регулирование экономических процессов вытекает из самой сущности государства. Государство с момента возникновения в силу своего предназначения как института, призванного выражать и реализовывать всеобщую волю всего населения и его интересы, наряду с комплексом других выполняет также ряд социальных и экономических функций [1, с.184].

Все вопросы, касающиеся государственной поддержки социально ориентированных некоммерческих организаций в России, регламентируются основным документом - Федеральным законом «О некоммерческих организациях» от 12 января 1996 № 7-Ф3 (да-
Багирова Елена Владиславовна

К.э.н., дочент, ФГБОУ ВО «Кемеровский государственный институт культуры»

Лазарева Маргарита Викторовна

К.п.н., старший преподаватель, ФГБОУ ВО «Кемеровский государственный институт культуры» elenabagirova@hotmail.com

Аннотация. В данной работе рассмотрены признаки социально ориентированных некоммерческих организаций, и представлены основные меры государственной поддержки социально ориентированных некоммерческих организаций. Определены основные государственные программы, поддерживающие деятельность социально ориентированных некоммерческих организаций.

Ключевые слова: государственная поддержка, социально ориентированные некоммерческие организации, государственное регулирование, ресурсный центр социально ориентированных некоммерческих организаций.

лее - Закон «О некоммерческих организациях») [5]. Адресность - это ключевая особенность социально ориентированных некоммерческих организаций. Обеспечение эффективной государственной поддержки социально ориентированных некоммерческих организаций требует выполнения четких критериев, которые позволяют отличить данные организации от других некоммерческих организаций. Исходя из закона «О некоммерческих организациях» социально ориентированные некоммерческие организации имеют следующие признаки, которые представлены для наглядности в виде схемы (рисунок 1).

Тенденцией последних лет в государственной поддержке социально ориентированных некоммерческих организаций является утверждение комплексных государственных программ [4, с. 75]. Данные программы поддержки в основном уже включают значительную часть предусмотренных законодательством форм поддержки.

В настоящее время существуют различные формы государственной поддержки социально ориентированных некоммерческих организаций (СО НКО) (рисуHок 2).

Также существует еще определенная особенность государственной поддержки СО НКО в РФ ею является 


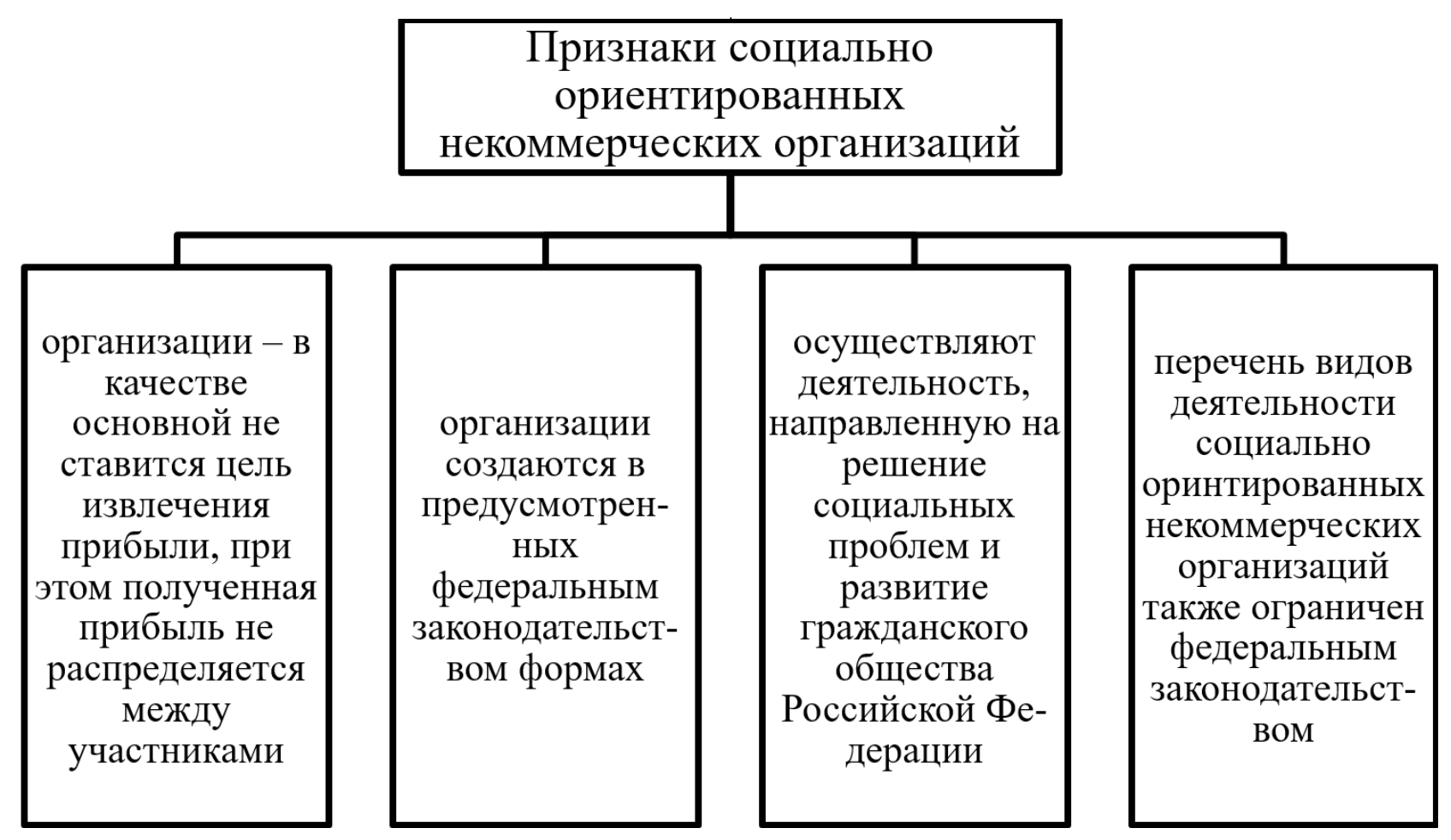

Рис. 1. Признаки социально ориентированных некоммерческих организаций

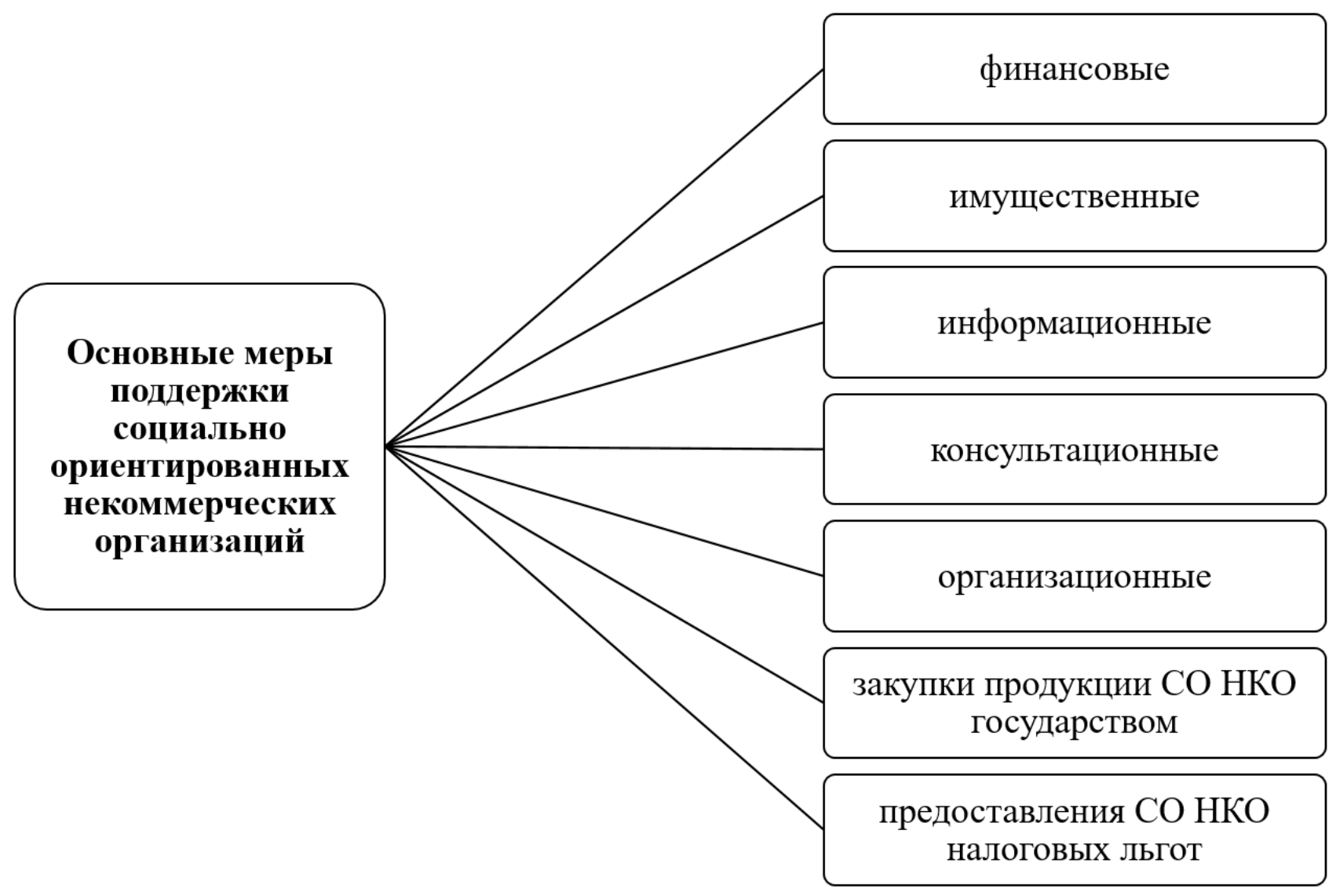

Рис. 2. Меры поддержки социально ориентированных некоммерческих организаций 


\section{Основные государственные программы, поддерживающие деятельность} СО НКО

\begin{tabular}{|c|c|c|c|}
\hline $\begin{array}{c}\text { Социальная } \\
\text { поддержка } \\
\text { граждан 2013- } \\
2024 \text { гг.» } \\
\text { Программа } \\
\text { содержит семь } \\
\text { взаимосвязанных } \\
\text { подпрограмм, } \\
\text { одна из которых - } \\
\text { «овышение } \\
\text { эффективности } \\
\text { государственной } \\
\text { поддержки } \\
\text { социально } \\
\text { ориентированных } \\
\text { некоммерческих } \\
\text { организаций» }\end{array}$ & $\begin{array}{c}\text { в рамках } \\
\text { национального } \\
\text { проекта } \\
\text { «Образование» } \\
\text { предусматривает- } \\
\text { ся привлечение } \\
\text { СО } \\
\text { некоммерческих } \\
\text { организаций к } \\
\text { оказанию } \\
\text { отдельных видов } \\
\text { услуг и оказанию } \\
\text { помощи для } \\
\text { родителей }\end{array}$ & $\begin{array}{c}\text { в рамках } \\
\text { федерального } \\
\text { проекта - } \\
\text { «Содеиствие } \\
\text { занятости женщин } \\
\text { - создание } \\
\text { условий } \\
\text { дошкольного } \\
\text { образования для } \\
\text { детей в возрасте } \\
\text { до трех лет» } \\
\text { поставлена задача } \\
\text { обновить } \\
\text { существующие } \\
\text { механизмы } \\
\text { поддержки } \\
\text { организаций } \\
\text { некоммерческого } \\
\text { сектора в сфере } \\
\text { дошкольного } \\
\text { образования }\end{array}$ & $\begin{array}{c}\text { Федеральный } \\
\text { проект «Старшее } \\
\text { поколение», } \\
\text { реализуемый в } \\
\text { рамках } \\
\text { национального } \\
\text { проекта } \\
\text { «Демография» } \\
\text { предусматривает- } \\
\text { ся создание сети } \\
\text { ресурсных } \\
\text { центров } \\
\text { подлержки } \\
\text { волонтерских } \\
\text { организаций, } \\
\text { специализирую - } \\
\text { щихся в } \\
\text { различных сферах }\end{array}$ \\
\hline
\end{tabular}

Рис. 3. Государственные программы поддержки СО НКО

многоуровневый характер поддержки. Согласно закону «O некоммерческих организациях», поддержка СО НКО осуществляется на трех следующих уровнях: федеральный, региональный и муниципальный.

Также важной особенностью является и многообразие видов деятельности социально ориентированных некоммерческих организаций. Существуют следующие основные виды деятельности СО НКО:

1. социальная поддержка и социальное обслуживание граждан;

2. помощь населению в преодолении последствий стихийных бедствий;

3. оказание юридической помощи гражданам и др.

В настоящее время инновационные механизмы поддержки так же коснулись и деятельности СО НКО. Данные инновации поплатились в деятельности ресурсных центров. Ресурсный центр СО НКО - это организация, которая оказывает информационную, консультационную, образовательную, организационную и иную ресурсную поддержку социально ориентированным некоммерческим организациям, которая также еще и содействует внедрению в их деятельность новых социальных и управленческих технологий, формированию среды, способствующей развитию и деятельности социально ориентированных некоммерческих организаций.

Опыт деятельности таких ресурсных центров НКО показывает положительную динамику в области развития некоммерческого сектора в России. Например, в Кузбассе существует два таких центра:

- Кемеровская региональная общественная организация «Ресурсный центр поддержки общественных инициатив» (информационная, консультационная, образовательная, финансовая, продвижение лучших практик СО НКО, работа по включенности СО НКО в сферу социальных услуг);

- Центр инноваций социальной сферы (информационная, финансовая, консультационная, образовательная, продвижение, популяризация лучших бизнес-моделей в социальной сфере) [2, с. 176].

В рамках государственной поддержки социально ориентированных некоммерческих организаций в РФ 
реализуются следующие виды государственных программ (рисунок 3).

На протяжении последних нескольких лет наблюдается значительное увеличение финансирования СО НКО с 4 млрд. руб. в 2014 году до 35 млрд. руб. в 2019 году., но при этом есть проблемы, которые следует решать. Такие, например, как недостаточность и неравномерность государственной поддержки по субъектом РФ, весьма сложное оформление отечности некоммерческой организации, невысокий уровень информационной поддержки. Все это конечно же препятствует развитию СО НКО.

\section{ЛИТЕРАТУРА}

1. Максимова С.Г. Социально ориентированные некоммерческие организации в Российской Федерации: состояние и перспективы развития: монография / Максимова С.Г., Ноянзина 0.Е., Гончарова Н.П.— Барнаул: Изд-во Алтайского гос. ун-та, 2013.— 206 с.

2. Мухамедиева С.А. Формирование кадрового потенциала как условие обеспечения качества социально-культурной деятельности в организациях сферы культуры / С.А. Мухамедиева // Вестник Кемеровского государственного университета культуры и искусств. 2018. № 44. С. — 175-184.

3. Нащёкина Е.В. Социально-ориентированные некоммерческие организации в России: монография / Елена Витальевна Нащёкина, Елена Витальевна Ким.- Москва: ВГУЮ, 2019. - 119 с.

4. Шмелева М.В. Правовое регулирование деятельности социально ориентированных некоммерческих организаций в Российской Федерации: административный и финансовый аспекты: монография / М.В. Шмелева.—Ульяновск: УГУ, 2020.— 166 с.

5. Федеральный закон «0 некоммерческих организациях» от 12 января 1996 № 7-Ф3. Консультант плюс. URL: http://www.consultant.ru/document/cons_ doc_LAW_8824/ (дата обращения: 12.05.2021).

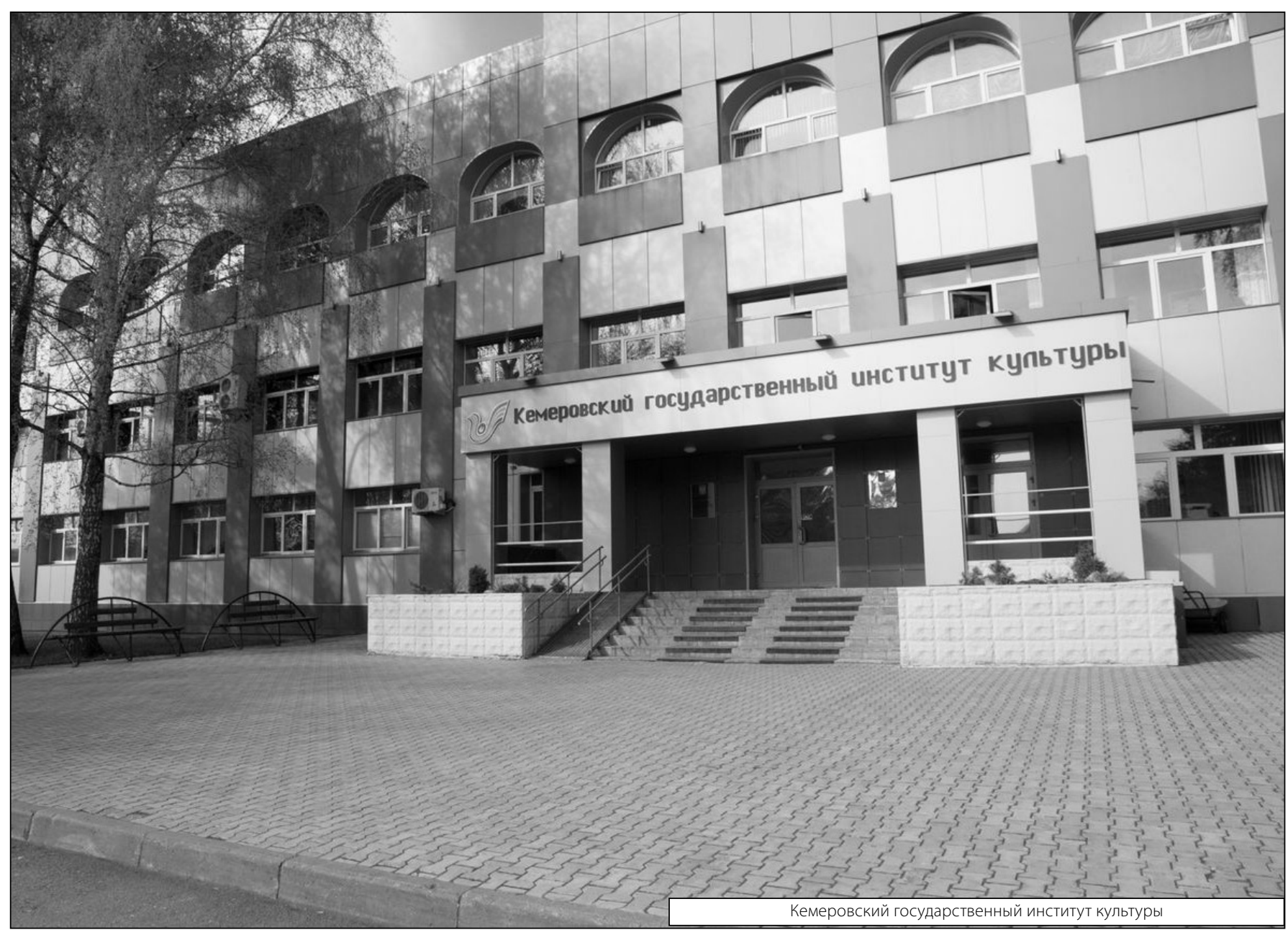

